\title{
Hysteroscopic Detection of Intrauterine Pathology in Women with Unexplained Infertility
}

\author{
ESSAM KHALIFA, M.D.; AHMED FAYK, M.D.; ESSAM RASHAD, M.D. and AHMED ALY, M.Sc. \\ The Department of Obstetrics \& Gynaecology Women's Health Hospital, Faculty of Medicine, Assiut University
}

\begin{abstract}
Background: Abnormalities of the uterus are relatively uncommon cause of infertility but should be considered, if no other reason, they can adversely affect the outcome of pregnancies achieved by successful treatment. The anatomic uterine abnormalities that may adversely affect fertility include congenital malformations, leiomyoma's, intrauterine adhesions, and endometrial polyps, but their reproductive implications are most unclear. One of the basic steps of an infertility workup is to evaluate the shape and regularity of the uterine cavity. Acquired uterine lesions, such as uterine fibroids, endometrial polyps, intrauterine adhesions, or all of these, may cause infertility by interfering with proper embryo implantation and growth. Congenital uterine malformations are also thought to play a role in delaying natural conception
\end{abstract}

Aim of Study: This study was designed to evaluate the role of hysteroscopy in women with unexplained infertility.

Patients and Methods: Women with unexplained infertility were included in this cross sectional study, evaluated with transvaginal sonography and diagnostic hysteroscopy. Diagnostic hysteroscopy was performed between the 7 th and $11^{\text {th }}$ day of the cycle. The criteria for hysteroscopic findings were based on the cervical canal, uterine cavity, endometrium, visualization of the tubal ostium and lesions of the utero-tubal junction. Patients were classified according to the hysteroscopy results into two groups: Patients with no abnormality detected $(n=49)$, patients with uterine abnormalities $(n=71)$.

Results: One hundred twenty women with unexplained infertility were included, all patients underwent diagnostic hysteroscopy. Based on hysteroscopic findings, 22 of them $(18.3 \%)$ were finally diagnosed to have polyps, 6 patients had cervical stenosis $(5 \%), 1$ patients have myomas $(.8 \%), 8$ patients had intrauterine synechia (7\%) and 19 patients had congenital uterine anomalies $(16 \%)$. Cervicitis was found in 12 cases $(10 \%)$, while 3 cases had endocervical cysts $(2.5 \%)$, cornu not accessible in 4 cases $(3.3 \%)$, while ostia not seen in 8 cases $(6.6 \%), 3$ cases had tight isthmus $(2.5 \%)$ and 3 cases had polypidal thickness at isthmus $(2.5 \%)$ while hysteroscopy results were found to have no abnormality in 49 patients $(40.8 \%)$.

Correspondence to: Dr. Essam Khalifa,

The Department of Obstetrics \& Gynaecology Women's Health Hospital, Faculty of Medicine, Assiut University
Conclusions: Routine hysteroscopy should be used as a basic part of the work-up for women with unexplained infertility.

Key Words: Hysteroscopy - Unexplained infertility.

\section{Introduction}

INFERTILITY is the inability of a couple to achieve pregnancy over an average period of one year (in a woman under 35 years of age) or 6 months (in a woman above 35 years of age) despite adequate, regular (3-4 times per week), unprotected sexual intercourse [1].

Female infertility affects estimated 48.5 million women in the world with the highest prevalence of infertility affecting people in South-Asia, SubSaharan Africa, North Africa/Middle East, Central or Eastern Europe or central Asia [2]

There are several adverse effects associated with infertility issue. It has been suggested as a cause of instability in the lives of couples in which a case-control study has reported that the rate of remarriage is 3.5 times higher amongst infertile women [3].

Unexplained infertility is defined as the lack of an obvious cause for a couple's infertility and the females' inability to get pregnant after at least 12 cycles of unprotected intercourse or after six cycles in women above 35 years of age for whom all the standard evaluations are normal $[4,5]$.

The average incidence of unexplained infertility has been reported to be approximately $15 \%$ [6] Ray showed that approximately $15 \%$ to $30 \%$ of infertile couples will be diagnosed with unexplained infertility after their diagnostic workup [7].

Basic investigations for female infertility include assessment of cervical, uterine, tubal and ovulatory factors. Traditionally, uterine shape and 
fallopian tubes were assessed by Hysterosalpingogram (HSG). However, hysteroscopy is being increasingly used for direct visualization of uterine cavity and is considered superior to HSG. Hysteroscopy is used to diagnose or treat problems of the uterus [8].

Hysteroscopy indications for infertile women include intracavitary abnormalities, such as sub mucous fibroids, endometrial polyps, uterine septum, adhesions, and retained products of conception. Hysteroscopy is a valuable diagnostic and therapeutic modality in the management of infertility. Hysteroscopy is the gold standard procedure for uterine cavity exploration It is widely accepted that a complete infertility workup should include an evaluation of the uterine cavity. Uterine abnormalities, congenital or acquired are implicated as one of the causes of infertility [9].

\section{Diagnostic hysteroscopy:}

All procedures were performed between the 7 th and $11^{\text {th }}$ day of the cycle. The procedure was carried out without anesthesia. A rigid $4 \mathrm{~mm}$ continuous flow Bettochi hysteroscope with 0-direction of view was inserted into the uterus (Karl Storz Endoscpy, Utrecht, Netherlands) [10] transcervically and the uterine cavity was expanded by irrigation with $0.9 \%$ saline solution. After introducing the hysteroscope through the internal uterine os, the uterine cavity was thoroughly scanned. The criteria for hysteroscopic findings were based on the following: (A) Cervical canal: Abnormalities of the cervix such as stenosis or polyps. (B) Uterine cavity: Adhesions, uterine malformations (septum and bicornuate uterus), polyps,submucous myomas. (C) Endometrium (1) adenomyosis: Although diagnostic hysteroscopy does not provide data regarding pathognomonic signs for adenomyosis, some evidence suggests that an irregular endometrium with endometrial defects, altered vascularisation and cystic hemorrhagic lesions are possibly associated with this entity. (2) Chronic endometritis: chronic endometritis is characterized by consistent association with stromal edema and either focal or diffuse hyperemia (red endometrium that was flushed with a white central point and was localized or scattered out the cavity, the "strawberry aspect"); in some cases, this finding is associated with endometrial micropolyps ( $\backslash 1 \mathrm{~mm}$ in size). (3) Hysteroscopic detection of focal or extensive endometrial thickening, irregular vascular network, architectural distortion and crowding of gland openings, were considered as endoscopic features consistent with hyperplasia [11]. (D) Visualization of the tubal ostium: Lesions of the uterotubal junction [12]

\section{Patients and Methods}

This study was conducted in Assiut University Women's Health Hospital. Patients attended outpatient infertility clinic suffering from 1ry or 2ry unexplained infertility. It was done from september 2015 till December 2016. 120 patients with unexplained infertility were included in the study.

Study design: The study was designed as cross sectional study.

\section{Inclusion criteria:}

Women selected for this study who initially diagnosed with unexplained infertility have all of the following criteria:

- Normal semen analysis: According to WHO, 2010:

- Volume: $1.5 \mathrm{ml}$.

- Total Sperm count: 39 million total.

- Sperm count: 15 million/ml.

- Motility: $40 \%$ total motility with progressive motility $32 \%$ (grade $\mathrm{a}+\mathrm{b}$ ).

- Vitality: $58 \%$ or more alive.

- Morphology: 4\% or more normally formed.

- PH: 7.2-8.0.

- White blood cells: Less than 1,000,000/ml.

\section{- Normal ovulation:}

- Regular menstrual cycles-menstrual periods that arrive every 24-35 days are more likely to be ovulatory than periods that occur more or less often.

- Ovulatory monitoring using transvaginal ultrasound.

- Serum progesterone: Detected on day21of the cycle (midluteal phase) can detect ovulation. Serum levels more than $3 \mathrm{ng} / \mathrm{ml}$ indicates ovulation.

- Good and healthy patent tube: Detected by using Hysterosalpingography and laparoscopy.

\section{Exclusion criteria:}

- Women with irregular menstrual cycles.

- Women using hormonal medication in the last 3 months.

- Any factor deviating the patient from being unexplained infertility as:
A- Male factor.
B- Tubal block.
C- Anovulation. 
D- Previous diagnosis of intrauterine anatomic abnormalities whether congenital or acquired.

E- Gynecological surgery in the last 6 months.

\section{Patients assessment:}

Full history taking includes personal, present, past, family, obstetric and menstrual history, Clinical examination includes pulse, blood pressure, temperature, chest, heart and abdominal examination, Gynecological examination and breast examination for galactorrhea, normal HSG was done 35 days after menstruation and hysteroscopy was done from 7 th-11 th day of menstruation.

\section{Sample size calculation:}

The overall prevalence of infertility was estimated to be $3.5-16.7 \%$. It is estimated that a standard fertility evaluation will fail to identify an abnormality in approximately $15 \%$ to $30 \%$ of infertile couples. Sample size was calculated using EPI-inf 2000 with confidence interval $95 \%$ and predictive prevalence $15 \%$ so sample size was 120 cases.

\section{Statistical analysis:}

Descriptive and analytical statistics were performed on IBM-compatible computer by using SPSS 11.5 software package under windows XP operating system. Continuous data were presented in the form of mean $\pm \mathrm{SD}$ and range for normally distributed data and Mean \pm SEM for nonparametric data distribution. Categorical data were presented in the form of number and percentage.

\section{Results}

This study included 120 women all complaining of unexplained infertility. The age ranged from 1842 years with a mean of $30.50 \pm 5.61$ SD. The BMI ranged from $17-32 \mathrm{~kg} / \mathrm{m} 2$ with a mean of $21.19 \pm 2.04$ SD (Table 1).

As regard the menstrual history, regular cycle's ranges from 24 to 35 days with a mean of $31.53 \pm$ 2.7 1and the duration of the menses ranges from 3 to 7 days with a mean of $4.20 \pm 1.05$. The age of menarche ranges from 12 to 16 years with a mean of 13.47 $\pm 0.71 \mathrm{SD}$ (Table 1).

Our patients complained of unexplained infertility, 81 complained of primary infertility, 39 of secondary infertility. The duration of infertility ranged from 1 to 20 years with a mean of $6.56 \pm 4.12$ SD (Table 1).
Table (1): Clinical characteristics of included women.

\begin{tabular}{lll}
\hline & \multicolumn{1}{c}{ No. $(\mathrm{n}=120)$} & $\%$ \\
\hline $\begin{array}{l}\text { Age: } \\
\text { Mean } \pm \text { SD (Range) }\end{array}$ & $30.50 \pm 5.61(18.0-42.0)$ & \\
Body mass index: & & \\
$\quad$ Mean \pm SD (Range) & $21.19 \pm 2.04(17.0-32.0)$ & \\
Age of menarche: & & \\
$\quad$ Mean \pm SD (Range) & $13.47 \pm 0.71(12.0-16.0)$ & \\
Length of the cycle: & & \\
$\quad$ P:Mean \pm SD (Range) & $4.20 \pm 1.05(3.0-7.0)$ & \\
$\quad$ C: Mean \pm SD (Range) & $31.53 \pm 2.71(24.0-35.0)$ & \\
Type of infertility: & & \\
$\quad$ Primary & & \\
$\quad$ Secondary & 39 & \\
Duration of infertility: & & \\
$\quad$ Mean \pm SD (Range) & $6.56 \pm 4.12(1.0-20.0)$ & \\
\hline
\end{tabular}

Table (2): Findings of hysteroscopy.

\begin{tabular}{|c|c|c|}
\hline & No. $(n=120)$ & $\%$ \\
\hline \multicolumn{3}{|l|}{ Ectocervix: } \\
\hline Normal & 110 & 91.7 \\
\hline Cervicitis & 10 & 8.3 \\
\hline \multicolumn{3}{|l|}{ Endo cervix: } \\
\hline Normal & 106 & 88.3 \\
\hline Polyp & 5 & 4.2 \\
\hline Endocervicitis & 8 & 6.7 \\
\hline Multiple shreads & 1 & 0.8 \\
\hline \multicolumn{3}{|l|}{ Endocervical canal: } \\
\hline Normal & 99 & 82.5 \\
\hline Polyp & 6 & 5.0 \\
\hline Adhesions & 2 & 1.7 \\
\hline Cyst & 3 & 2.5 \\
\hline Stenosis & 6 & 5.0 \\
\hline Endocervicitis & 4 & 3.3 \\
\hline \multicolumn{3}{|l|}{ Isthmus: } \\
\hline Normal & 114 & 95.0 \\
\hline Polypoidal thickness & 3 & 2.5 \\
\hline Tight isthmus & 3 & 2.5 \\
\hline \multicolumn{3}{|l|}{ Endometrium: } \\
\hline Atrophic epithelium & 1 & 0.8 \\
\hline Congested endometrium & 6 & 5.0 \\
\hline Mottleled endometrium & 1 & 0.8 \\
\hline Multiple shreads & 1 & 0.8 \\
\hline Proliferative & 111 & 92.5 \\
\hline \multicolumn{3}{|l|}{ Uterine cavity: } \\
\hline Normal & 78 & 65.0 \\
\hline Arcuat uterus & 1 & 0.8 \\
\hline Broad fundus & 1 & 0.8 \\
\hline Depressed fundus & 10 & 8.3 \\
\hline Duplication of upper part of ut.cavity & 1 & 0.8 \\
\hline Polyp & 15 & 12.5 \\
\hline Sub endometrial stations & 1 & 0.8 \\
\hline Submucousmyoma arising from ltbord. & 1 & 0.8 \\
\hline Uterine adhesion & 5 & 4.2 \\
\hline Uterine adhesion- polyp & 1 & 0.8 \\
\hline Uterine septum & 6 & 5.0 \\
\hline \multicolumn{3}{|l|}{ Cornu: } \\
\hline Accessible & 116 & 96.7 \\
\hline Not accessible & 4 & 3.3 \\
\hline \multicolumn{3}{|l|}{ Ostia: } \\
\hline Not seen & 8 & 6.7 \\
\hline Seen & 112 & 93.3 \\
\hline
\end{tabular}




\section{Finding of hysteroscopy:}

All patients were subjected to diagnostic hysteroscopy, 22 of them (18.3\%) were finally diagnosed to have polyps, 6 patients had cervical stenosis $(5 \%), 1$ patients have myomas $(.8 \%), 8$ patients had intrauterine synechia (7\%) and 19 patients had congenital uterine anomalies $(16 \%)$. Cervicitis was found in 12 cases $(10 \%)$, while 3 cases had endocervical cysts $(2.5 \%)$, cornu not accessible in 4 cases $(3.3 \%)$, while ostia not seen in 8 cases $(6.6 \%)$, 3 cases had tight isthmus $(2.5 \%)$ and 3 cases had polypidal thickness at isthmus $(2.5 \%)$ while hysteroscopy results were found to have no abnormality in 49 patients $(40.8 \%)$ (Table 2$)$.

One hundred twenty women (120) who were initially diagnosed unexplained infertility had normal HSG examined with hysteroscopy, intrauterine pathologies detected in 71/120 with false negative rate of HSG $59.2 \%$ (Table 3 ).

According to our study, specificity of HSG seems to be $40.8 \%$ as shown in (Table 3 ).

Table (3): Hysteroscopy versus HSG.

\begin{tabular}{ccc}
\hline \multirow{2}{*}{ HSG } & \multicolumn{2}{c}{ Hysteroscopy } \\
\cline { 2 - 3 } & Positive & Negative \\
\hline Negative & $71(59.2 \%)$ & $49(40.8 \%)$ \\
\hline
\end{tabular}

\section{Discussion}

Uterine cavity pathologies may affect endometrial receptivity and implantation. The evaluation of the uterine cavity therefore is an important part of the infertility workup for the infertile women [13] . Office hysteroscopy is a powerful diagnostic tool for visualizing the cervical canal and uterine cavity and is usually performed to confirm suspected uterine abnormalities and detect any intrauterine pathology [14]

Sharma reported that hysterosalpingography is a simple, non-invasive procedure that enables visualization of the uterine cavity contour and revealing or ruling out anomalies that include different types of intrauterine defects. In addition, HSG provide information about tubal patency or blockage. However, HSG is an indirect means of demonstrating the interior of the uterus [15]. While hysteroscopy is a safe and quick examination $(<5 \mathrm{~min})$ for the direct and accurate diagnosis of intrauterine abnormalities. It permits direct visualization of the interior of the uterine cavity, revealing the nature and localization of endocavitary lesions. It allows diagnosis of functional and organic ab- normalities; and also allows guidance of endometrial biopsies and cultures for histologic evaluation $[16,17]$

In the current study, we examined 120 women with unexplained infertility, normal HSG with office hysteroscopy. It was found that $59 \%$ of patients have intrauterine pathologies including polyps $(18.3 \%)$, congenital uterine anomalies $(16 \%)$, intrauterine adhesions (7\%) and Cervicitis was found in $(10 \%)$. Our patients have a large percentage of abnormal uterine findings because this hospital has a tertiary infertility unit and therefore patients were selected.

In the current study, hysteroscopy was done in the early proliferative phase, so there were no difficulties in the procedure and no need for cervical dilatation; this makes the procedure compliant for the patients. Some patients were received pervaginal misoprostol $400 \mathrm{mcg}$ before the procedure. All patients examined with office hysteroscopy at little time with minimal discomfort and at a much lower cost than in an operating room and without hospital admission. There were no need for preoperative surgical fitness or anesthesia and patient can go home immediately after the procedure.

The current study is observational study; hysteroscopist can detect any subtle intrauterine lesion, but can't deal with it in the same set as this need prepared operative set under anesthesia. In few cases some patient were uncooperative during procedure and were overly anxious. Also limitations to this study that we don't include patient with positive findings for HSG, so we can't detect the sensitivity. No analgesia was used before or during the procedure, so there was little discomfort from the patient.

There are many randomized studies published in the literature but their results are conflicting. Some studies reported significant intrauterine findings on office hysteroscopy agree with our study. A study in which 54 patients with unexplained infertility given a non-steroidal antiinflammatory drug (NSAID) and a prophylactic antibiotic 30 minutes before the procedure were examined with office hysteroscopy using 30 degree lens, $(61.2 \%)$ had normal and $(38.8 \%)$ had abnormal hysteroscopic findings [18]. Another study consistent with our study, carried out at fertility care unit in central hospital using $30^{\circ}$ oblique hysteroscopy, 200 women with unexplained infertility underwent office hysteroscopy, intrauterine pathologies was detected in (33\%) [19] 
The accuracy of hysteroscopy for detecting uterine abnormalities in infertile patients has been discussed by various studies. In a observational study, 100 women's with unexplained infertility were examined with office hysteroscopy and abnormal hysteroscopic findings were found in 56\%. Hysteroscopy was performed in an operative theatre by using $2.9 \mathrm{~mm} 30^{\circ}$ bettochi hysteroscopy with HD camera and under general anesthesia [20] Which can be explained as using anesthesia may help more in the diagnosis.

Intrauterine abnormalities were found in $32.12 \%$ of selected patients examined with diagnostic hysteroscopy under general anesthesia [21]. Wang reported a false negative rate of $35.4 \%$ in study examined 79 selected patients with office hysteroscopy at Outpatient infertility clinic of a tertiary medical center [22]. Also intrauterine findings were detected in $36 \%$ of 100 selected women's examined with office hysteroscopy [23]

Fatemi in his study which inconsistent with the present study, a total of 678 unselected, asymptomatic, infertile women were examined with office hysteroscopy and the overall prevalence of any unsuspected intrauterine abnormality is $11 \%$ [24] Fatemi included general infertile patient. The examination could not be accomplished due to patient intolerance, the procedure was continued under Para cervical block, using a lidocaine injection $(2 \times 2 \mathrm{ml}, 2 \%)$ using a 5 -mm outer-diameter continuous flow bettocchi hysteroscope with $30^{\circ}$ direction of view. In our study patient were selected as unexplained infertility and the procedure was done using a $3.7-\mathrm{mm}$ outer-diameter continuous flow rigid mini-hysteroscope with $0^{\circ}$ direction of view without anesthesia.

Preutthipan and Linasmita reported an intrauterine lesions detected by hysteroscopy in 4 out of 50 patients in whom HSG were normal with false negative rate $8 \%$ [25]. Preutthipan included general infertile patient. The study was done in a different demographic area. In their study patients were examined using a standard rigid $5 \mathrm{~mm}$ hysteroscope under general anesthesia using propofol as total intravenous anesthesia (TIVA). In the majority of their cases the uterine cavity was distended with carbon dioxide using an electronic Hamou hysteroflat or providing a flow rate of up to $50 \mathrm{~mL} / \mathrm{min}$ at a pressure of $100 \mathrm{mmHg}$. While in our study accurate selection of patient who was examined without anesthesia using saline $0.9 \%$ as distension media.

\section{Conclusion and Recommendations:}

We have analyzed results of office hysteroscopy done for 120 women's initially diagnosed as unexplained infertility and abnormal intrauterine pathology was detected in 71 women's with false negative rate of HSG $59 \%$.

Based on high false negative rate of HSG (59\%) in our study, we recommend that hysteroscopy can be added as a step in the routine infertility work up. Hysteroscopy has an advantage of being able to treat a lesion once detected in the same session.

Targeted endometrial biopsy should be always indicated as a complementary exam after hysteroscopy to improve accuracy during endometrial evaluation. Compared with D\&C, hysteroscopic biopsy has better ability to detect endometrial polyps and sub mucous myomas [26]

\section{References}

1- COOPER T.G., NOONAN E. and S. VON ECKARDSTEIN: Hum. Reprod, 16: 231-55, 2010.

2- MASCARENHAS M.N., FLAXMAN S.R., BOERMA T., VANDERPOEL S. and STEVENS G.A.: National, regional, and global trends in infertility prevalence since 1990: A systematic analysis of 277 health surveys. PLoS. Med., 9: 1001356, 2012.

3- JUMAYEV I., HARUN-OR-RASHID M., RUSTAMOV O., ZAKIROVA N., KASUYA H. and SAKAMOTO J. Social correlates of female infertility in Uzbekistan. Nagoya. J. Med. Sci., 74: 273-83, 2012.

4- MOSHER W.D. and PRATT W.F.: Fecundity and infertility in the United States: Incidence and trends (Editorial) Fertil. Steril., 56: 192-5, 1991.

5- BERKOWITZ KING R. and DAVIS J.: Introduction: Health disparities in infertility. Fertil. Steril., 85: 842-5, 2006.

6- TEMPLETON A.A. and PENNEY G.C.: The incidence, characteristics, and prognosis of patients whose infertility is unexplained. Fertil. Steril., 37: 175-82, 1982.

7- RAY A., SHAH A., GUDI A. and HOMBURG R.: Unexplained infertility: An update and review of practice. Reprod. Bio. Med. Online, 24: 591-602, 2012.

8- KUMAR S., ASWATHI R.T. and GOKHALE N.: Assessment of uterine factor in infertile women: Hysterosalpingography vs Hysteroscopy. MJAFI, 60: 39-41, 2003.

9- BROWN S.E., CODDINGTON C.C., SCHNORR J., TONER J., GIBBONS W. and OEHNINGER S.: Evaluation of outpatient hysteroscopy, saline infusion hysterosonography, and hysterosalpingography in infertile women: A prospective, randomized study. Fertil Steril., 74: $1029-34,2000$

10- ABDELAZIM I.A. and ELEZZ A.A.: Complementary roles of hysteroscopyand saline infusion hysterosonography in uterine cavity assessment before in vitro fertilization. Asian. Pac. J. Reprod, 1 (1): 13-16. 
11- GARUTI G., CELLANI F., GARZIA D., COLONNELLI M. and LUERTI M.: Accuracy of hysteroscopic diagnosis of endometrial hyperplasia: A retrospective study of 323 patients. J. Minim. Invasive. Gynecol., 12 (3): 247-253, 2005.

12- VALLE R.F. and SCIARRA J.J.: Intrauterine adhesions: Hysteroscopic diagnosis, classification, treatment, and reproductive outcome. Am. J. Obstet. Gynecol., 158: 1459-70, 1988.

13- KIRAN H., KAPLANOLU M. and CETIN M.T.: Sonohysterography of the uterine cavity with hysteroscopic correlation in the investigation of infertility. J. Turkish. German. Gynecol. Assoc., 9: 94-6, 2007.

14- CORSIGNANI P.G. and VERCELLINI P.: Gynaecological endocrinology. Preface. Best. Pract. Res. Clin. Obstet. Gynaecol., 22: 233, 2008.

15- SHARMA J., K. ROY, M. PUSHPARAJ and S. KUMAR: Hysteroscopic findings in women with primary and secondary infertility due to genital tuberculosis Inte. J. of Gyne. \& Obstet., 104: 49-52, 2004.

16- BALMACEDA J.P. and CIUFFARDI I.: Hysteroscopy and assisted reproductive technology. Obstet. Gynecol. Clin. North. Am., 22: 507-18, 1995.

17- MERVIEL P., MERGU J.L., SANANES S., ANTOINE J.M., SALAT-BAROUX J. and UZAN S.: Place de l'hystéroscopiedans le diagnostic et le traitement de l'infertilité. Presse. Med., 29: 1302-10, 2000.

18- BARATI M., MAHVASH ZARGAR, SARA MASIHI, LEILA BORZOO and BAHMAN CHERAGHIAN: Office Hysteroscopy in Infertility. Int. J. of Fertil \& Steril., 3: 17-20, 2009.

19- ELBAREG A.M., ESSADI F.M., ANWAR K.I. and ELMEHASHI: Value of hysteroscopy in management of unexplained infertility. Asian. Pacific. J. of Reproduction, 3: 295-303, 2014.
20- JAIN N., MANCHANDA R., LEKHI A. and CHITHRA.: Role of Hysteroscopy in Evaluation of Infertility: A Retrospective Study of 100 Cases. J. Gynecol., 1: 000117 , 2016.

21- VAID KEYA, SHEILA MEHRA, MITA VERMA, SANDHYA JAIN, ABHA SHARMA and SRUTI BHASKARAN.: Pan Endoscopic Approach- Hysterol-aparoscopy as an Initial Procedure in Selected Infertile Women. J. Clin. Diagn. Res., 8: 95-103, 2014.

22- WANG C.W., LEE C.L., LAI Y.M., TSAI C.C., CHANG M.Y. and SOONG Y.K.: Comparison of hysterosalpingography and hysteroscopy in female infertility. J. Am. Assoc. Gynecol. Laparosc., 3: 581-5, 1996.

23- ELORABY N.M., ELNORY M.A., SHARAF ELDEEN A.A. and SAFAA M.M.: Diagnostic hysteroscopy as a primary tool in basic infertility workup. Int. J. of Adv. Res., 4: 1716-21, 2016.

24- FATEMI H.M, KASIUS J.C., TIMMERMANS A., VAN DISSELDORP J., FAUSER B.C., DEVROEY P., et al.: Prevalence of unsuspected uterine cavity abnormalities diagnosed by office hysteroscopy prior to in vitro fertilization. Hum. Reprod, 25: 1959-65, 2010.

25- PREUTTHIPAN S. and LINASMITA V.: A prospective comparative study between hysterosalpingography and hysteroscopy in the detection of intrauterine pathology in patients with infertility. The J. Obst. And. Gynec. Research, 29: 33-7, 2003.

26- PEDRO ADRIANA, MO NICA JORGE, EDSON FONSECA and LUCIA COSTA-PAIVA JOSE' R.: Gabiatti, Alexandre Viola Department of Gynecology and Obstetrics, State University of Campinas, R. Alexander Fleming 101, 13083-881 Campinas, SP, Brazi International. Congress. Series., 1271: 259- 62, 2004. 


$$
\begin{aligned}
& \text { J\$ , k4V\$, } \$ \text {, }
\end{aligned}
$$

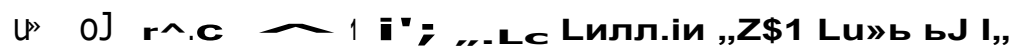

人 ь

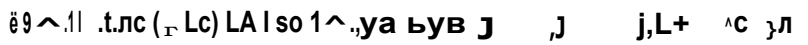

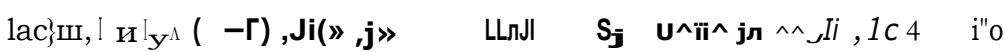

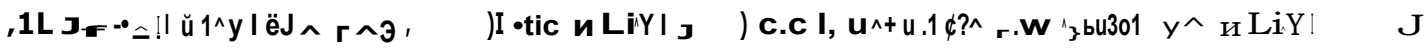

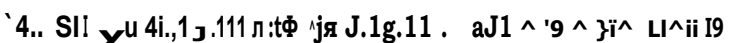

$$
\text { Y: : =II }, \text { JL I, Sa... }
$$

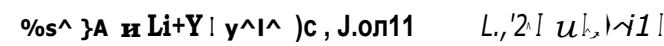

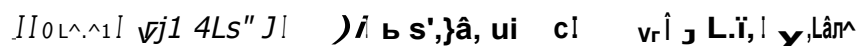

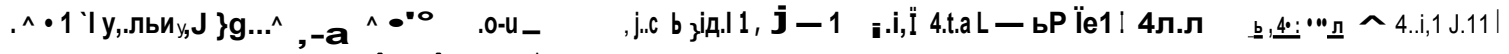

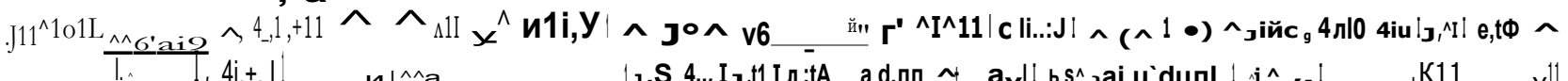

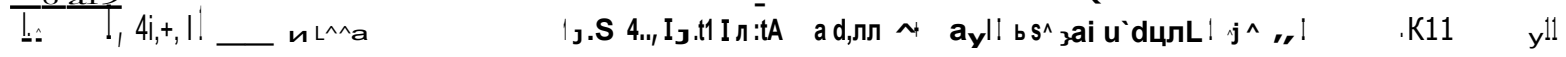

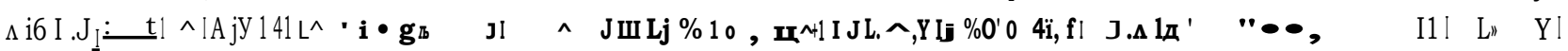

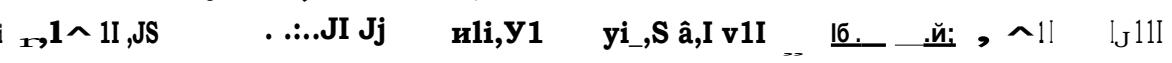

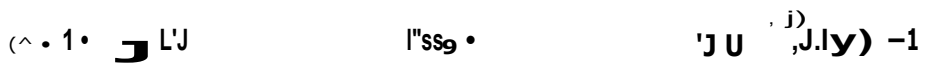
$\cdot \wedge 1, \wedge 10 \cdot \cdot 4 \wedge \wedge 511-$

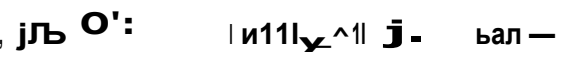
"J.0/: y1л y.10 Ic, L': , .,Ic I ySî : $s^{1}$ g.h̆]э ol ${ }^{1}-$ LJ!, А С $\%$. A yS İ: $4 \boldsymbol{л}_{\mathbf{j}}$ и1! $A-V$ s : PH :4/ b j.A. $1 /$ ă.J $J$ J\%v J'O 1 ................. v" ^^.০І.ліJ। 1 டцЛ -

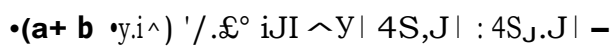
$:, \wedge 1,11, \mathbf{j} \quad \mathbf{j}_{\mathbf{j}} \mathbf{j j} \mathbf{j}-\mathbf{1}$

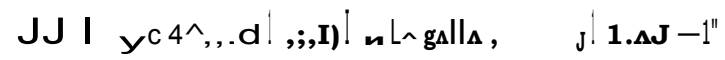

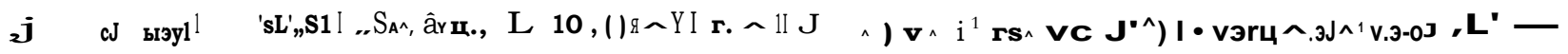

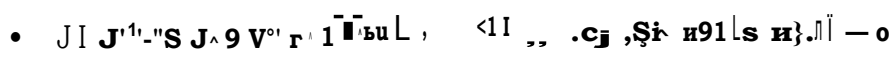
$\bullet, 1, \wedge: \sim, \wedge, \mathrm{Y} \mid$ JyLOo

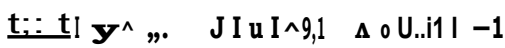

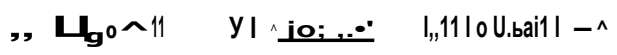

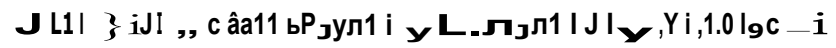
B:11 I ,1.4It - 


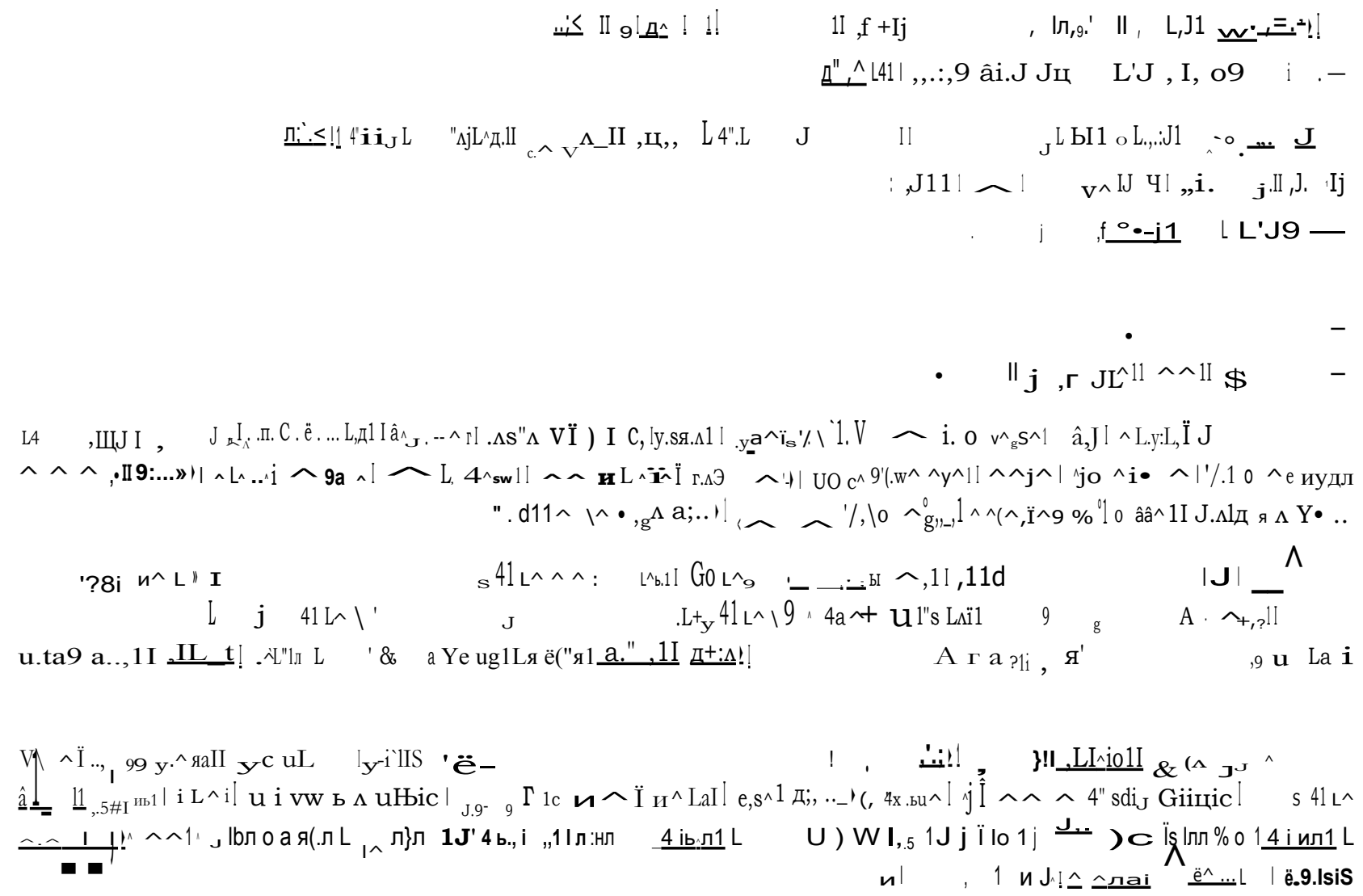

